\title{
Valuing Authenticity: Exploring the Role of Consumer Traits in Restaurant Choice: An Abstract
}

\author{
Juliann Allen
}

\begin{abstract}
The notion that authenticity increases value remains an accepted concept in the authenticity literature. But does that hold to be true across every consumer? Some consumers may not care about the presence of authenticity. Depending on one's goals in purchasing a product or service, the state of whether a brand manager has a passion for doing his or her job may not matter. Authenticity is defined as a trait of being intrinsically motivated, with actions driven from being "true to self." Grounded in self-determination theory, the current research examines how the intrinsic motivation of brand managers affects consumers' value assessments of a restaurant. The focus remains on consumer perceptions of authenticity. For example, brand managers may demonstrate authenticity by giving the perception that they are more product oriented rather than consumer oriented. Authenticity also has been found to have a connection to uniqueness. Consumers who are authentic and less motivated by the thoughts and actions of others tend to have a greater desire to acquire unique products. Consumers who avoid businesses that are highly frequented by the majority of consumers may be more likely to value an authentic restaurant. Further, consumers aiming to self-identify with products or services that are unpopular may look to authenticity as a way to achieve similarity avoidance. Also, value orientation may play a role in valuing authenticity. Consumers dining out for an experience rather than to simply complete the task of eating a meal may value authenticity more.

Specifically, the conceptual framework proposes that perceived authenticity and popularity of a restaurant positively influence a restaurant's perceived value. Perceived value positively influences behavioral intention. Additionally, similarity avoidance and consumer value orientation moderate the relationship between the independent variables of perceived authenticity and popularity and the mediator of perceived value. Expected findings include the result that those high in similarity avoidance will consider perceived authenticity as providing more value than those low in similarity avoidance. Also, the author expects that consumers who highly value authenticity will place greater importance on hedonic value in restaurants.
\end{abstract}

\footnotetext{
J. Allen $(\varangle)$

Louisiana Tech University, Ruston, LA, USA

e-mail: jma074@latech.edu
} 